The Longevity Economy ${ }^{\circledR}$ Outlook

\section{North Dakota}

\section{State Outlook}

As North Dakota's population ages, older residents will play a critical role in the state's economic recovery and growth. Even after accounting for the impact of COVID-19, North Dakota's aging population will continue to make economic and social contributions that benefit people of all ages, and the growth of this age group will fuel innovation and new market solutions. Policymakers, business leaders, and elected officials must ensure programs and policies are in place to support and grow this economic engine.

\section{Key findings:}

North Dakota's 50-plus population creates outsize economic impact and will drive economic growth for the next 30 years. In 2018, the 50-plus population accounted for $33 \%$ of North Dakota's population, yet contributed $44 \%$ - or $\$ 29$ billion-of the state's total GDP. Their activities also supported 267,000 jobs and generated $\$ 16$ billion in wages and salaries. Their contribution to GDP is forecast to reach $\$ 87$ billion in 2050 -almost $42 \%$ of the state's projected GDP-when people 50-plus will account for $38 \%$ of the population.

The purchasing power of North Dakota's 50-plus population will generate tax revenue for decades to come. In 2018, the market activities of people 50 -plus supported $\$ 2.0$ billion in state and local taxes (38\% of North Dakota's total). That figure will more than triple to $\$ 6.9$ billion by 2050 .

Where do people age 50 -plus live?

(\%) share by county in 2018

$24 \%-34 \%$

$34 \%-39 \%$

$39 \%-44 \%$

$44 \%-49 \%$

$49 \%-56 \%$

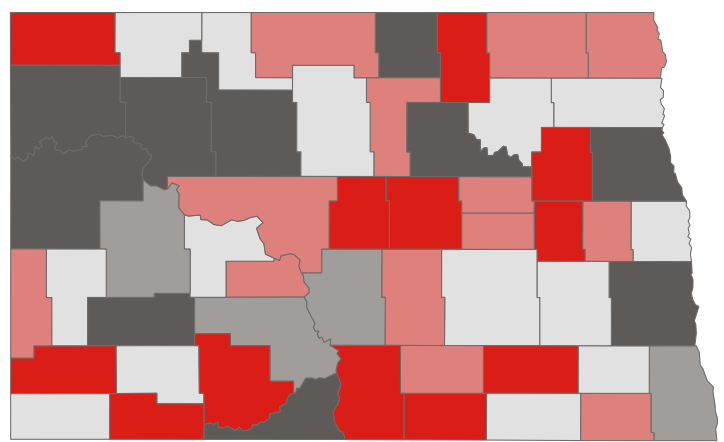

Overview: Economic impact of the 50-plus population

\begin{tabular}{l|r|r|r|c}
\hline & \multicolumn{2}{|c|}{2018} & \multicolumn{2}{c}{2050} \\
\cline { 2 - 5 } & Impact & $\begin{array}{r}\% \text { of } \\
\text { total }\end{array}$ & Impact & $\begin{array}{c}\% \text { of } \\
\text { total }\end{array}$ \\
\hline State GDP & $\$ 29$ billion & 44 & $\$ 87$ billion & 42 \\
\hline Jobs & 267,000 & 46 & 278,000 & 43 \\
\hline Wages and salaries & $\$ 16$ billion & 51 & $\$ 44$ billion & 48 \\
\hline State and local taxes & $\$ 2.0$ billion & 38 & $\$ 6.9$ billion & 39 \\
\hline
\end{tabular}

"\% of total" refers to 50 -plus impact as a percentage of each category.

The 50 -plus cohort will grow from $33 \%$ to $38 \%$ of the population by 2050

(Thousands)

(0) \% of the population within each age group - 50-64 65-74 -75-plus

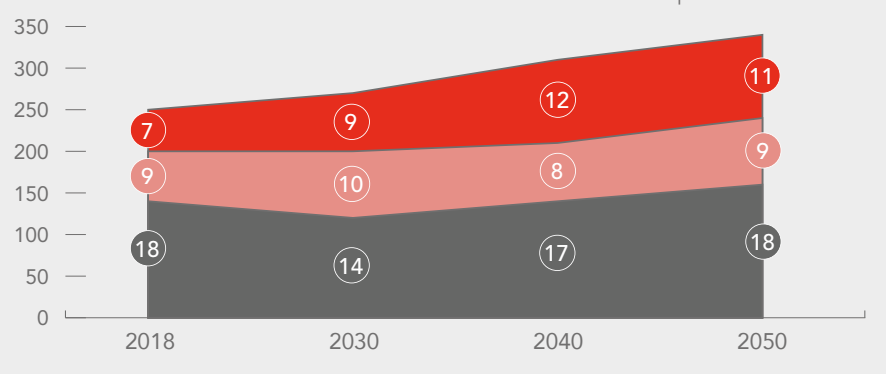

The 50-plus population fuels economic growth, stimulates jobs, and creates opportunities

Economic impact of the 50-plus through 2050

GDP (\$ billion)

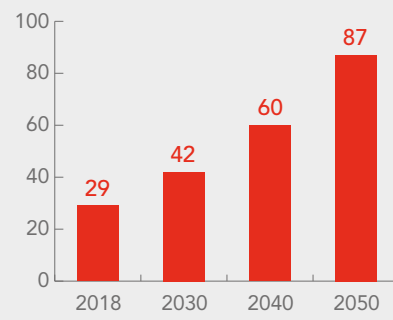

State and local taxes ( $\$$ billion)

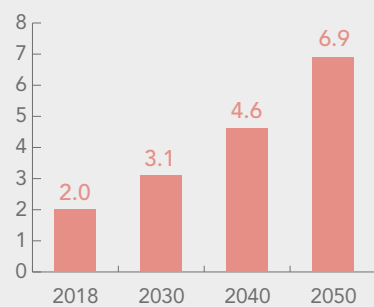

Wages and salaries (\$ billion)

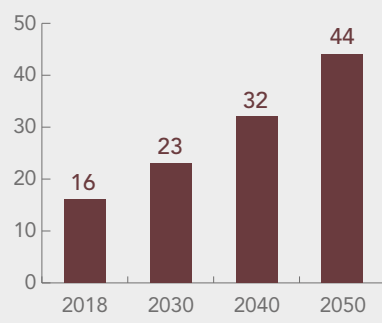

Jobs (thousand)

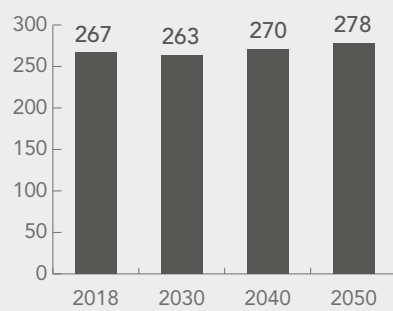




\section{North Dakota}

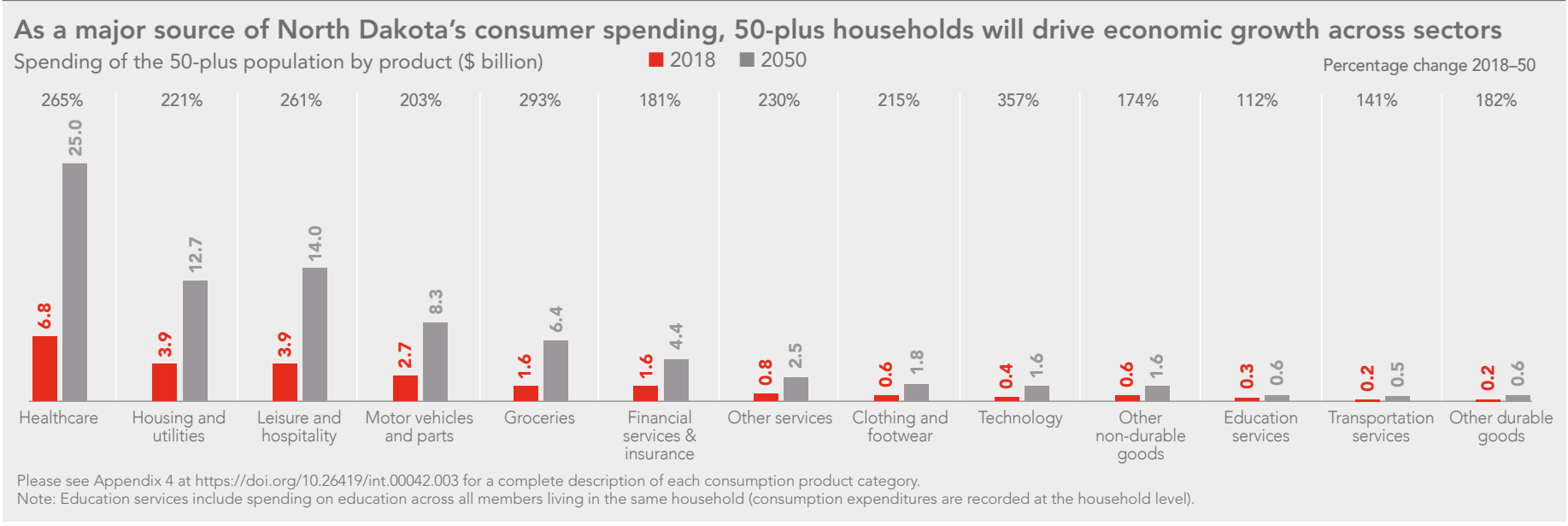

\section{Unpaid contributions}

Beyond their economic contributions, the 50-plus cohort also spends time engaging in vital activities like volunteering and caregiving for children and adults. The 50-plus population in North Dakota contributed $\$ 296$ million in volunteering activities and $\$ 1.5$ billion in unpaid caregiving in 2018, with the average person spending 56 hours on volunteering and over 440 hours on caregiving over the entire year.

The 50-plus population provides $\$ 2$ billion in unpaid contributions

Value of unpaid activities, 2018 ( $\$$ billion)

(Values may not sum due to rounding)

- Under-50 $\quad$ 50-plus

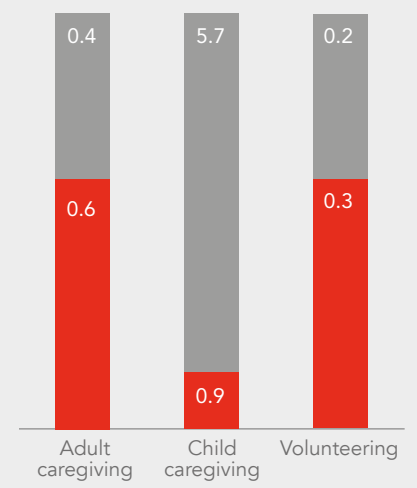

50-plus households accounted for 56 cents of every dollar spent in North Dakota in 2018this will grow to 61 cents (61\%) by 2050

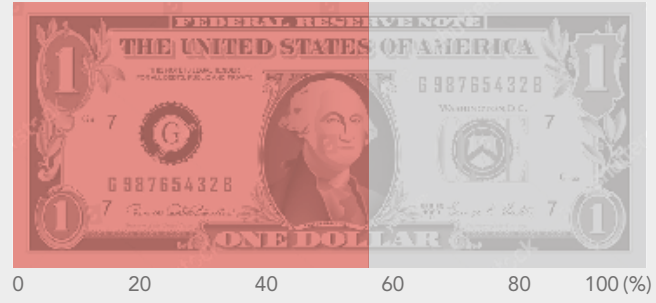

50-plus share of every dollar spent, for select categories (\%) $-2018=2050$

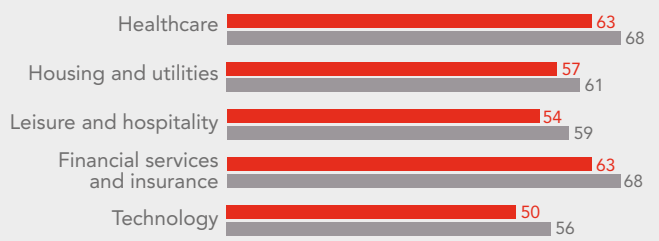

The market activities of North Dakota's 50-plus population create jobs, wages, and salaries

In 2030, the 50-plus population's activities will support 263,000 jobs in North Dakota, driving employment growth across all age groups and industries. Most of these jobs will be created in health services; wholesale and retail trade; government; and finance, insurance, and real estate (see chart on right).

Labor force: People age 50-plus will continue to play a significant role as part of North Dakota's workforce: by 2030, 50-plus workers in the state are projected to number 135,000 , representing $32 \%$ of the state's total labor force.
Which sectors will see biggest jobs impact in 2030 ? Number of jobs supported by 50 -plus activities and \% of sector Health services

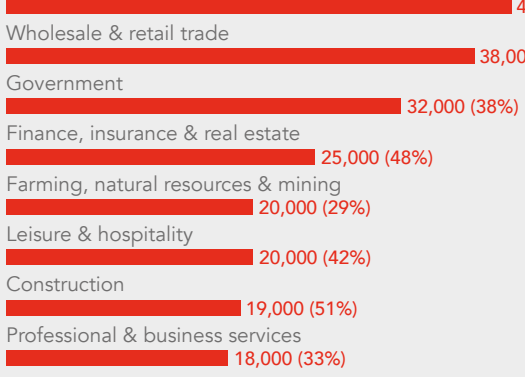

Methodology: This state profile details the contribution of the 50-plus population, both in-state and through interstate commerce, to North Dakota's economy. The overall impact includes the direct effects of their spending, work contributions, and taxes paid. It also includes the ripple effects this generates-via business supply chains and through the wages and spending of other workers. All forecasts account for the effects of COVID-19 on U.S. demographic and economic projections. These forecasts were informed by data from the Centers for Disease Control and Prevention, the Bureau of Economic Analysis, Bureau of Labor Statistics, and The Economist Intelligence Unit's macroeconomic forecasts. For further details see: http://www.aarp.org/longevity.

Sources: Economic impact and forecasts (EIU, Regional Economic Models, Inc. [REMI]); Population by age (REMI, U.S. Census Bureau); 50-plus population share by county (U.S. Census Bureau 2018); Spending (EIU, Bureau of Labor Statistics, Bureau of Economic Analysis, REMI); Jobs impact by sector (EIU, REMI): Unpaid contributions (EIU, American Time Use Survey, AARP's Valuing the Invaluable: 2019 Update, Bureau of Labor Statistics).
For more information about the Longevity Economy download our free report. It offers as a roadmap for companies to tap into this growing market.

http://www.aarp.org/longevity https://doi.org/10.26419/int.00044.035
With 